This item was submitted to Loughborough's Research Repository by the author.

Items in Figshare are protected by copyright, with all rights reserved, unless otherwise indicated.

\title{
The role of emotion regulation for coping with school-based peer- victimisation in late childhood
}

PLEASE CITE THE PUBLISHED VERSION

http://dx.doi.org/10.1016/j.paid.2016.11.035

\section{PUBLISHER}

(C) Elsevier

VERSION

AM (Accepted Manuscript)

\section{PUBLISHER STATEMENT}

This work is made available according to the conditions of the Creative Commons Attribution-NonCommercialNoDerivatives 4.0 International (CC BY-NC-ND 4.0) licence. Full details of this licence are available at: https://creativecommons.org/licenses/by-nc-nd/4.0/

\section{LICENCE}

CC BY-NC-ND 4.0

\section{REPOSITORY RECORD}

Gardner, Sarah E., Lucy R. Betts, James Stiller, and Janine Coates. 2019. "The Role of Emotion Regulation for Coping with School-based Peer-victimisation in Late Childhood". figshare. https://hdl.handle.net/2134/23404. 
Running Head: EMOTION REGULATION VICTIMISATION COPING

The Role of Emotion Regulation for Coping with School-Based Peer-Victimisation in Late Childhood

Sarah E. Gardner ${ }^{1}$, Lucy R. Betts ${ }^{1}$, James Stiller ${ }^{1}$, Janine Coates ${ }^{2}$

${ }^{1}$ Department of Psychology, Nottingham Trent University

${ }^{2}$ School of Sport, Health and Exercise Science, Loughborough University

Author Note

*Corresponding Author:

Sarah E. Gardner, Division of Psychology, Nottingham Trent University, Burton Street, Nottingham, NG1 4BU. Email: sarah.gardner@ntu.ac.uk 
Running Head: EMOTION REGULATION VICTIMISATION COPING

\begin{abstract}
The current research examined the role of two emotion regulation processes, cognitive reappraisal and emotion suppression, on maladaptive victimisation coping following schoolbased peer-victimisation in late childhood $(n=443)$. The relationship between emotion regulation and maladaptive coping was also tested for serial mediation effects, linking peervictimisation and school loneliness. Results showed that poor emotion regulation in children was positively associated with maladaptive peer-victimisation coping. Moreover, the relationship between cognitive reappraisal and maladaptive coping was found to mediate the relationship between peer-victimisation experiences and school loneliness. These findings have implications for the development of school-based peer-victimisation intervention strategies that focus on improving children's emotional competencies.

Keywords: Peer-victimisation; emotion regulation; coping; emotion suppression; cognitive reappraisal.
\end{abstract}


Running Head: EMOTION REGULATION VICTIMISATION COPING

\section{Introduction}

Recent figures suggest that peer-victimisation is a major issue within the United Kingdom, such that 1 in 4 children under the age of 11 actively seek support for problems pertaining to bullying (NSPCC, 2015). The severity of this situation is further exacerbated when considering the potential adjustment issues associated with peer-victimisation, including elevated levels of depression, anxiety, and loneliness (Hansen, Steenberg, Palic, \& Elklit, 2012). However, whilst it is clear that peer-victimisation can have a strong negative impact on a child, not all children are affected in the same manner (Ttofi, Bowes, Farrington, \& Losel, 2014). Specifically, the coping strategies that victimised children may employ have been found to mediate the relationship between peer-victimisation and maladaptive outcomes (for review see Hansen, et al., 2012). In particular, using internalising (e.g., self-blame and rumination) as a coping strategy is associated with a wide range of poor outcomes following peer-victimisation (Harper, 2012; Houbre et al. 2010). It is less clear, however, why some children choose to use this maladaptive form of coping following peer-victimisation. It is important to understand the factors that may influence a child's propensity to utilise maladaptive coping strategies, particularly when considering the impact for the development of future prevention and intervention strategies that tackle peer-victimisation. Children's regulation of emotions represents one possible explanatory individual difference, but is yet to be explored within peer-victimisation coping literature.

The present study therefore examined (a) the relationship between emotion regulation and maladaptive peer-victimisation coping and (b) the indirect effect of peer-victimisation on school loneliness via emotion regulation and maladaptive coping (serial mediation). 
Running Head: EMOTION REGULATION VICTIMISATION COPING

\subsection{Coping with peer-victimisation}

Coping is a mechanism by which an individual attempts to solve, minimise, or tolerate a stressor (Snyder, 1999). Regarding peer-victimisation specifically, coping strategies have broadly been categorised as adaptive/effective or maladaptive/ineffective. For example, social support, whether it is received from friends, family, or teachers, has been shown to reduce future victimisation (Smith, Talamelli, Cowie, Naylor, \& Chauhan, 2004). In addition, children who use problem-solving strategies, such as conflict resolution, are more likely to experience less future victimisation (Flanagan et al., 2013). Contrastingly, coping strategies such as retaliation and internalising are associated with continued victimisation and poor outcomes (Harper, 2012; Houbre, Tarquino, Lanfranchi, 2010). Frequently peer-victimised children commonly use maladaptive internalising coping, which includes strategies such as self-blame and rumination (Andreou, 2001). It has been found that victimised children who use internalising coping responses are at a greater risk of poor psychosocial adjustment, including loneliness, depression, and low self-worth (Harper, 2012; Houbre et al., 2010). Due to the double-risk associated with using internalising coping (i.e., increased likelihood of continued victimisation and poor adjustment) the current study examined internalising as a measure of maladaptive coping.

Despite the wealth of knowledge on how children cope with peer-victimisation, there is less research on which children use a particular victimisation coping strategy, especially those that are deemed maladaptive. A child's emotions and emotional state is one individual difference that has received increasing attention in the field of peer-victimisation coping literature. Research has found that, as expected, victimised children are more likely to display negative emotions such as fear, sadness, and anger (Hunter \& Borg, 2006; Mahady-Wilton, Craig, \& Pepler, 2000). These negative emotions can in turn predict coping response patterns; 
Running Head: EMOTION REGULATION VICTIMISATION COPING

for example, children who experience fear are more likely to seek social support whereas children who experience anger are more likely to retaliate (Hunter, Boyle, \& Warden, 2004; Kochenderfer-Ladd, 2004; Mahady-Wilton et al. 2000). However, whilst there is evidence to suggest emotions play a role in the coping response, the processes behind the display of emotions, often known as emotion regulation, is frequently ignored in peer-victimisation coping literature. Cole, Martin, and Dennis (2004) argue that it is important to distinguish between emotional display and emotion regulation, and that the relationship between the two may not be linear. The regulation of emotion is particularly pertinent in late childhood (Garnefski, Kraaij, Spinhoven, 2001; Zimmer-Gembeck \& Skinner, 2011), and thus the current study addresses this gap in the literature by examining the role of emotion regulation on a child's propensity to use maladaptive coping strategies following peer-victimisation.

\subsection{Emotion regulation}

Emotion regulation is the complex process responsible for initiating, inhibiting, or modulating one's emotions in response to a particular situation (Gross, 1998). The ability to regulate one's emotions is particularly important during later childhood where children make huge developmental changes in regards to cognitive, social, and emotional skills (Rose \& Rudolph, 2006; Steinberg, 2005). However, despite this developmental period marking a critical turning point for many children, emotion regulation research is predominately focused on infancy and early childhood (for review see Zeman, Cassano, Perry-Parrish, \& Stegall, 2006). Moreover, many studies examining emotion regulation in children have been criticised for lacking a clear theoretical framework (Gullone, Hughes, King, \& Tonge, 2010). In response to the raised theoretical concerns, the current study draws upon Gross' (1998) process orientated model. This model stipulates two sub-types of emotion regulation processes: (1) cognitive reappraisal and (2) emotion suppression. Cognitive reappraisal is a cognitive change process whereby the individual attempts to modify their thoughts to alter 
Running Head: EMOTION REGULATION VICTIMISATION COPING

the emotional response (Webb, Miles, \& Sheeran, 2012). It is also an antecedent-focused response, activating before the full emotional response kicks in. In contrast, suppression is a behaviourally orientated tactic in which emotion-expressed behaviour is decreased when emotionally aroused (Gross, 2013). This is a response-focused process, and is activated when the emotion is already underway (Gross \& John, 2003). The utilisation of these two regulation processes can have alternative outcomes and non-significant correlations between the processes are reported suggesting that they are distinct (Gross \& John, 2003); thus it is important to examine them concurrently. In relation to socio-emotional outcomes, the use of suppression and reappraisal are both associated with depressive symptoms, with children who display high levels of emotion suppression and/or low levels of cognitive reappraisal more likely to experience symptoms of depression (Gullone \& Taffe, 2012) than those children who are able to regulate their emotions.

Although previous peer-victimisation research has explored the role of a child's emotional state on their coping following victimisation (e.g., Hunter \& Borg, 2006; MahadyWilton et al., 2000), the regulatory processes that underlie the display of these emotional responses has not yet been examined. The current study therefore examined the role of two emotion regulation processes (cognitive reappraisal and emotion suppression) as predictors of maladaptive coping, which in turn was predicted to mediate the relationship between peervictimisation and school loneliness (as an indicator of a socioemotional outcome). The proposed model can be seen in Figure 1 whereby the authors propose that that there will be an indirect effect via emotion dysregulation, maladaptive coping, or via both emotion regulation and maladaptive coping. 
Fig 1. Proposed conceptual model

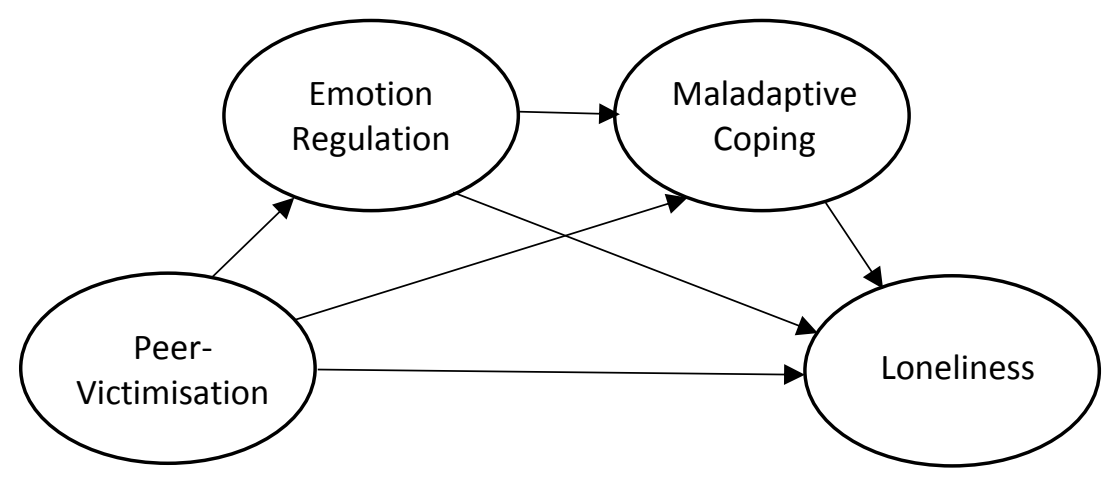

Following the proposed conceptual framework, it was anticipated that poor emotion regulation strategies would predict maladaptive coping. The relationship between emotion regulation and maladaptive coping would then serve as serial mediators for the relationship between peer-victimisation and school loneliness. Due to the multi-faceted nature of peervictimisation (Mynard \& Joseph, 2000), four types of peer-victimisation experiences were examined: social, verbal, physical, and attack on property. In addition, owing to limited emotion regulation research in late childhood populations, the sample was drawn from children aged between 9 and 11 years. The hypotheses therefore read as follows:

H1.

Both emotion regulation processes, suppression and cognitive reappraisal, will predict maladaptive coping. High levels of emotion suppression will increase the propensity to use maladaptive coping, whereas high levels of cognitive reappraisal will decrease the propensity to use maladaptive coping.

H2. 
Running Head: EMOTION REGULATION VICTIMISATION COPING

Poor emotion regulation and maladaptive coping will act as serial and parallel mediators for the relationship between peer-victimisation and school loneliness.

\section{Method}

\subsection{Participants}

Data were collected from 443 children (58\% girls, 1 child identifying as transgender; $\mathrm{M}_{\text {age }}=$ 9.79 years, $\left.\mathrm{SD}_{\mathrm{age}}=0.64\right)$ during the first term of the UK school academic year. Participants were recruited from 8 primary schools across BLANKED, U.K and were either in Year 5 $(n=184)$ or Year $6(n=259)$. The majority of children were of a White British background.

Parental consent was obtained via an opt-out and opt-in procedure, dependent on the schools preferred method. Seven of the eight schools chose to use the opt-out procedure. The overall response rate was $97.7 \%$, and $85.5 \%$ within classrooms.

\subsection{Measures}

\subsubsection{Peer-victimisation}

The 16-item Multidimensional Peer-Victimisation Scale (Mynard \& Joseph, 2000) measured 4 types of victimisation experiences: (1) social (e.g., "Tried to make my friends turn against me; $\alpha=.80$ ), (2) verbal (e.g., "Called me names"; $\alpha=.78)$, (3) physical (e.g., "Punched me"; $\alpha=.80$ ) and (4) attack on property (e.g., "Deliberately damaged something that belonged to me"; $\alpha=.83$ ). Participants were asked to state how frequently they had experienced an act of victimisation since the beginning of the school term on 5-item response scale from 1 (Never) to 5 (Afew times a week).

\subsubsection{Maladaptive Coping}


Running Head: EMOTION REGULATION VICTIMISATION COPING

The 6-item passive/internalising coping sub-scale $(\alpha=.73)$ from the 'What would I do' selfreport coping scale (Kochenderfer-Ladd \& Pelletier, 2008) was used to measure maladaptive coping (e.g., "Blame yourself for doing something wrong"). Children responded on a 3-point scale $(1=$ Never $; 2=$ Sometimes $; 3=$ Most of the time $)$ to indicate how often they used the strategy.

\subsubsection{Emotion Regulation}

The 10-item Emotion Regulation Questionnaire for Children and Adolescents (ERQ-CA; Gullone \& Taffe, 2012) measured emotion suppression (e.g., "I keep my feelings to myself", $\alpha=.72$ ) and cognitive reappraisal (e.g., "When I am worried about something I make myself think about in a way that helps me feel better", $\alpha=.84$ ) on a 5-point Likert scale, from 1 (Strongly Disagree) to 5 (Strongly Agree).

\subsubsection{School Loneliness}

A 4-item measure of school loneliness was constructed from the Loneliness and Social Dissatisfaction Questionnaire (Asher, Hymel, \& Renshaw, 1984), e.g. "I am lonely at school”. Children responded using a 5-point Likert scale ranging from 1 (Strongly Disagree) to 5 (Strongly Agree); $\alpha=.89$.

\subsection{Procedure}

Following approval from the university's College Research Ethics Committee, primary schools in BLANKED were contacted to take part in the research. All interested schools were invited to one-to-one meeting with the researcher and were provided with parental letters to send home at least two weeks prior to the researcher visiting the school. 
Running Head: EMOTION REGULATION VICTIMISATION COPING

Participants completed the questionnaire in their normal classroom environments under the supervision of the researcher. The children were informed that their answers would remain confidential, and that no individual answers would be shared with anybody except the research team. The participating children were given a debrief sheet to take home and all children received a sticker as a thank you for their time.

\section{Results}

\subsection{Overview of analyses}

A series of structural equation models were specified using MPlus 7.2 (Múthen \& Múthen, 2012) to examine whether the effect of peer-victimisation on school loneliness operated indirectly via emotion regulation and maladaptive coping (serial mediation effect; Hayes, 2012). Due to the ordinal nature of the indicators for peer-victimisation and coping, the Weighted Least Squares Mean and Variance adjusted (WLSMV) estimation was used. The WLSMV is a robust estimator, which can handle missing data and does not assume normal distribution of variables (Brown, 2006). Eight models were specified to examine the combination of each emotion regulation process (cognitive reappraisal and suppression) and type of peer-victimisation (social, verbal, physical, and attack on property).

In order to assess model fit, the following fit statistics were used as recommended in a review by Schreiber, Nora, Stage, Barlow, and King (2006). Chi-square ratio tests were used rather than the $p$-value associated with the chi-square statistic, due to the oversensitivity of the $p$-values with larger sample sizes. A ratio of $X^{2}$ to $d f \leq 2$ or 3 is deemed acceptable. Comparative Fix Index (CFI) and Tucker-Lewis Index (TLI) were used as comparative fit indices with acceptable values of $\geq .95$. Root Mean Squared Error of Approximation (RMSEA) confidence intervals between .06 to.08 and Weighted Root Mean Square Residual (WRMR) values less than .90 also indicate acceptable model fit. The indirect effects of 
Running Head: EMOTION REGULATION VICTIMISATION COPING

emotion regulation and maladaptive coping were evaluated using bias-corrected bootstrapped confidence intervals (Preacher \& Hayes, 2008).

Pearson's correlations and the descriptive statistics (means and standard deviations) for all variables are presented in Table 1.

Table 1

Correlation matrix and descriptive statistics $(n=443)$

\begin{tabular}{|c|c|c|c|c|c|c|c|c|}
\hline & $\begin{array}{c}\text { Physical } \\
\text { PV }\end{array}$ & $\begin{array}{c}\text { Verbal } \\
\text { PV }\end{array}$ & $\begin{array}{l}\text { Social } \\
\text { PV }\end{array}$ & $\begin{array}{l}\text { Property } \\
\text { PV }\end{array}$ & $\begin{array}{c}\text { Cognitive } \\
\text { Reapprais } \\
\text { al }\end{array}$ & $\begin{array}{l}\text { Suppressi } \\
\text { on }\end{array}$ & $\begin{array}{l}\text { Maladapti } \\
\text { ve Coping }\end{array}$ & $\begin{array}{c}\text { School } \\
\text { Lonelines } \\
\mathrm{S} \\
\end{array}$ \\
\hline Physical PV & & $.56 * *$ & $.50 * *$ & $.61 * *$ & $-.17 * *$ & .07 & $.25^{* *}$ & $.32 * *$ \\
\hline Verbal PV & & - & $.65^{* *}$ & $.61 * *$ & $-.21 * *$ & $.14 * *$ & $.38 * *$ & $.43^{* *}$ \\
\hline Social PV & & & - & $.60 * *$ & $-.20 * *$ & .08 & $.35^{* *}$ & $.40^{* *}$ \\
\hline Property PV & & & & - & $-.16^{* *}$ & $.11 *$ & $.26^{* *}$ & $.36^{* *}$ \\
\hline $\begin{array}{l}\text { Cognitive } \\
\text { Reappraisal }\end{array}$ & & & & & - & .02 & $-.23 * *$ & $-.21 * *$ \\
\hline Suppression & & & & & & - & $.19 * *$ & $.26 * *$ \\
\hline $\begin{array}{l}\text { Maladaptive } \\
\text { Coping }\end{array}$ & & & & & & & - & $.47^{* *}$ \\
\hline$M$ & 5.52 & 5.40 & 6.91 & 5.59 & 22.08 & 11.75 & 10.50 & 7.36 \\
\hline$S D$ & 2.61 & 3.01 & 3.40 & 2.80 & 5.41 & 3.83 & 2.80 & 3.91 \\
\hline
\end{tabular}

Note. $\mathrm{PV}=$ Peer-Victimisation

$* p<.05, * * p<.01$.

3.2 Maladaptive coping on emotion regulation (suppression and cognitive reappraisal).

To test $\mathrm{H} 1$ a simple linear regression was run in MPlus 7.2. The results are presented in Table

2. Both emotion regulation strategies were found to significantly predict maladaptive coping

$(p<.01$ level). As expected, high levels of cognitive reappraisal were associated with lower

levels of maladaptive coping use. Emotion suppression had a positive association with 
Running Head: EMOTION REGULATION VICTIMISATION COPING

maladaptive coping, such that high levels of suppression predicted high levels of maladaptive coping use.

Table 2.

Summary of multiple regression statistics for predictor variables $(n=443)$

\begin{tabular}{cccc}
\multicolumn{5}{c}{ Summary of multiple regression statistics for predictor variables $(n=443)$} & \\
\hline Variable & $\mathrm{B}$ & $\mathrm{SE}(\mathrm{B})$ & $\beta$ \\
\hline Suppression & 0.27 & 0.09 & $0.29^{* *}$ \\
Cognitive & -0.38 & 0.07 & $-0.32^{* *}$ \\
Reappraisal & & & \\
\hline
\end{tabular}

Note $* * p<.001 \mathrm{R}^{2}=.17$

\subsection{Indirect effects via emotion regulation and maladaptive coping}

To test the second hypothesis and the model in Figure 1, eight structural models were specified to examine the indirect effect of peer-victimisation on school loneliness via emotion regulation and maladaptive coping (i.e., Peer-Victimisation Type $\rightarrow$ Emotion Regulation Process $\rightarrow$ Maladaptive Coping $\rightarrow$ School Loneliness). The unstandardized results for each of the eight models are presented in Table 3. All models had a good fit, and met the criteria outlined by Schreiber et al. (2006). The $\mathcal{X}^{2} / d f$ ratios ranged between 1.68 to 1.78, CFI/TLI values were between $.95-.96$, the 95\% RMSEA CI were between .03-.05, and the WRMR ranged between $.84-.90$ for all models. 
Running Head: EMOTION REGULATION VICTIMISATION COPING

Table 3

Unstandardised 95\% bias-corrected confidence intervals for model pathways and indirect effects $(n=443)$

\begin{tabular}{|c|c|c|c|c|c|c|c|c|c|c|c|}
\hline \multirow{2}{*}{$\begin{array}{l}\text { Model } \\
\text { No. }\end{array}$} & \multirow{2}{*}{$\begin{array}{c}\text { IV } \\
\text { Peer } \\
\text { Victimisation } \\
\text { Type }\end{array}$} & \multirow{2}{*}{$\begin{array}{c}\text { M1 } \\
\text { Emotion } \\
\text { Regulation } \\
\text { Process }\end{array}$} & \multicolumn{9}{|c|}{ Pathways } \\
\hline & & & $\mathrm{IV} \rightarrow \mathrm{DV}$ & $\mathrm{IV} \rightarrow \mathrm{M} 1$ & $\mathrm{IV} \rightarrow \mathrm{M} 2$ & $\mathrm{M} 1 \rightarrow \mathrm{M} 2$ & $\mathrm{M} 1 \rightarrow \mathrm{DV}$ & $\mathrm{M} 2 \rightarrow \mathrm{DV}$ & $\begin{array}{c}\text { Indirect } 1 \\
\text { (via M1) }\end{array}$ & $\begin{array}{c}\text { Indirect } 2 \\
\text { (via M2) }\end{array}$ & $\begin{array}{c}\text { Indirect } 3 \\
\text { (via M1 } \\
\text { and M2) }\end{array}$ \\
\hline 1 & Physical & Reappraisal & $.095, .385$ & $-.224,-.078$ & $.100, .325$ & $-.64,-.14$ & $-.461, .104$ & $.566,1.09$ & $-.009, .056$ & $.073, .279$ & $.015, .073$ \\
\hline 2 & Physical & Suppression & .121.399 & $-.029, .225$ & $.112, .307$ & $.094, .315$ & $.096, .498$ & $.568,1.24$ & $-.005, .070$ & $.092, .296$ & $-.005, .041$ \\
\hline 3 & Verbal & Reappraisal & $.190, .497$ & $-.232,-.085$ & $.253, .500$ & $-.522,-.056$ & $-.423, .101$ & $.436, .971$ & $-.014, .064$ & $.154, .364$ & $.006, .050$ \\
\hline 4 & Verbal & Suppression & $.170, .478$ & $.092, .352$ & $.241, .478$ & $.027,, 245$ & $.041, .448$ & $.411,1.04$ & $.009, .112$ & $.153, .385$ & $.004, .041$ \\
\hline 5 & Social & Reappraisal & $.056, .422$ & $-.212,-.068$ & $.219, .464$ & -.516, -.018 & $-.449, .110$ & $.459,1.01$ & $-.015, .062$ & $.143, .359$ & $.003, .052$ \\
\hline 6 & Social & Suppression & $.129, .462$ & $-.033, .214$ & $.234, .478$ & $.073, .320$ & $.103, .508$ & $.428,1.08$ & $-.015, .071$ & $.151, .383$ & $-.007, .033$ \\
\hline 7 & Property & Reappraisal & $.143, .446$ & $-.220,-.043$ & $.185, .446$ & $-.577,-.050$ & $-.447, .091$ & $.425, .860$ & $-.014, .060$ & $.106, .302$ & $.002, .052$ \\
\hline 8 & Property & Suppression & $.123, .430$ & $.013, .306$ & $.163, .424$ & $.052, .293$ & $.068, .464$ & $.455,1.10$ & $-.006, .091$ & $.120, .340$ & $-.003, .046$ \\
\hline
\end{tabular}

Note. Bootstrap Draws $=5000$.

$\mathrm{IV}=$ independent variable $\mathrm{M} 1$ = mediator variable 1 (emotion regulation process), M2 = mediator variable 2 (maladaptive coping),

$\mathrm{DV}=$ dependent variable (school loneliness). Indirect $1=$ indirect effect via mediator 1 only, Indirect $2=$ indirect effect via mediator 2 only, Indirect $3=$ indirect effect via mediator 1 and mediator 2 .

3 s.f. are reported due indirect 3 estimates

$\mathrm{p}<.05$ confidence intervals in boldface. 
Running Head: EMOTION REGULATION VICTIMISATION COPING

All models containing the cognitive reappraisal emotion regulation process (models $1,3,5$ and 7) supported hypothesis 2 . Specifically, it was found that higher levels of peervictimisation was associated with lower levels of cognitive reappraisal. This in turn predicted higher levels of maladaptive coping, which in turn predicted higher levels of school loneliness (i.e., Peer-Victimisation Type $\rightarrow$ Cognitive Reappraisal $\rightarrow$ Maladaptive Coping $\rightarrow$ School Loneliness).

In regards to emotion suppression, significant serial mediation effects were only found in one model (model 4; [95\% CI: 0.004, 0.041]). Model 4 identified a positive association between verbal victimisation and emotion suppression i.e., higher levels of verbal victimisation predicted higher levels of emotion suppression. Subsequently, children's emotion suppression scores were positively associated with maladaptive coping, which then predicted higher levels of school loneliness (i.e., Verbal Peer-Victimisation $\rightarrow$ Emotion Suppression $\rightarrow$ Maladaptive Coping $\rightarrow$ School Loneliness).

The effect sizes for models containing significant serial mediation effects (model 1, 3, 4,5 , and 7) were relatively small, ranging from $3.7 \%$ to $7.4 \%$ of the total effect. Comparably larger effect sizes were found for the indirect effect via only maladaptive coping (i.e., PeerVictimisation Type $\rightarrow$ Maladaptive Coping $\rightarrow$ School Loneliness; Effect sizes $=33.9 \%$ to $44.3 \%$ ), highlighting the importance of the maladaptive coping style as an explanatory factor for the relationship between peer-victimisation and school loneliness.

All eight models also included indirect effects via only emotion suppression or cognitive reappraisal (i.e., Peer-Victimisation Type $\rightarrow$ Emotion Regulation $\rightarrow$ School Loneliness), but only one effect was found to be statistically significant (model 4). This effect 
Running Head: EMOTION REGULATION VICTIMISATION COPING

was via emotion suppression, which mediated the relationship between verbal victimisation and school loneliness [95\% CI: $0.1,0.11]$.

Finally, as all measures were self-report, Podsakoff, MacKenzie, Jeong-Yeon, and Podsakoff's (2003) latent common variable procedure for testing common method variance was followed. The significance of all paths in the models remained unchanged, suggesting that common method variance did not affect the study's findings.

\section{Discussion}

The purpose of this study was to explore the role of children's emotion regulation in maladaptive coping following school-based peer-victimisation. The study addressed theoretical limitations within peer-victimisation coping literature by focusing on the role of two emotion regulation strategies, cognitive reappraisal and emotion suppression from Gross' (1998) process orientated model.

The study's findings supported the first hypothesis (H1) that children's emotion regulation processes would predict maladaptive coping. Cognitive reappraisal was the strongest predictor in the model, whereby lower levels of reported cognitive reappraisal of emotions were associated with higher levels of maladaptive coping. In contrast, high levels of reported emotion suppression were associated with higher levels of maladaptive coping. These findings are consistent with previous research, suggesting that poor regulation of emotions, using either cognitive reappraisal or suppression, are concomitant with negative implications (Gross \& John, 2003). Previous peer-victimisation coping literature has predominately examined the role of negative emotions rather than the associated regulation processes (Hunter \& Borg, 2006; Kochenderfer-Ladd, 2004). The current study therefore builds on this literature by identifying two specific emotion regulation processes associated with poor victimisation coping. 
Running Head: EMOTION REGULATION VICTIMISATION COPING

The second hypothesis $(\mathrm{H} 2)$ was partially supported, with the relationship between cognitive reappraisal and maladaptive coping acting as a serial mediator between all four types of peer-victimisation experiences (verbal, social, physical, and attack on property) and school loneliness. Regarding emotion suppression, hypothesis two was only supported in the model containing verbal victimisation. These findings suggest that antecedent-focused (cognitive reappraisal) processes, rather than response-focused (emotion suppression) processes, are more important for reducing the negative effects of peer-victimisation. Previous research and theory has indicated that antecedent coping may be a preferable route towards psychological well-being (Gross, 1998), and thus the current findings support this model.

Kochenderfer-Ladd (2004) suggests that victims of peer-victimisation engage in similar patterns of emotion processing, regardless of the type of victimisation. The findings support this claim for the models containing cognitive reappraisal, but not for the models examining emotion suppression. The association found between verbal victimisation and emotion suppression may be due to the way in which verbal victimisation experiences are perceived by children. For example, verbally victimised children are less likely to report the incident than children who have been victimised via other means (Elsea, 2001). This could be due to peer-rejection being a key component for verbal victimisation (Larsen et al., 2012), and therefore suppression may be being used to manage these relationship difficulties rather than using alternative means of responding, such as reporting the victimisation.

As previously discussed, there is scant literature regarding the individual differences associated with poor victimisation coping. The current study therefore contributes to building this vital knowledge base by identifying the role of two emotion regulation processes. Whilst the proportional effect sizes for the serial mediation estimates were relatively small, the models are still of theoretical and practical importance, identifying potential pathways and 
Running Head: EMOTION REGULATION VICTIMISATION COPING

risk factors of school loneliness, following peer-victimisation. The implications of the study relate to victim-focused anti-bullying intervention programmes. For example, emotion coaching has been used in schools to help children self-regulate their own emotions (Katz et al., 2012), with recent UK-based research suggesting that this intervention programme promotes the development of emotional competencies and enhances relationships (Rose, McGuire-Snieckus, \& Gilbert, 2015). The findings from the current study emphasise the importance of emotion coaching for children, in particular the development of skills that promote cognitive reappraisal of emotions.

One potential limitation of the study is the application of self-report measures in the study. Although the relationships were tested for common method variance using Podsakoff's et al's (2003) recommended technique, there are obvious limitations with regards to asking children to self-report on constructs such as peer-victimisation and emotion regulation. In regards to emotion regulation, a number of previous studies in this area have used observational methods to assess children's emotional response to peer-victimisation (e.g., Mahady-Wilton et al., 2000). However, these studies have observed the display of a child's emotions, rather than the underlying regulatory processes. Alternative measurement methods do exist, for example using fMRI (McRae et al., 2012) or heart rate monitors (Hessler \& Fainsilber-Katz, 2007), but self-report still remains the most validated and reliable available method (Aldao, Nolen-Hoeksema, \& Schweizer, 2010). In regardps to future research, we suggest that studies should focus on replicating the current findings across the developmental span. Children's emotion regulation processes are not static and change throughout development (Cole et al., 2004), and therefore examining the role of emotion regulation for coping with peer-victimisation in other age-groups is of importance.

In conclusion, this study addresses gaps in the literature pertaining to understanding the role of emotion regulation processes, namely cognitive reappraisal and suppression, in 
Running Head: EMOTION REGULATION VICTIMISATION COPING

children's peer-victimisation maladaptive coping choices. The findings suggest that poor cognitive reappraisal of emotions is associated with an increased likelihood of using maladaptive coping strategies, in turn this relationship mediates the relationships between peer-victimisation and school loneliness. Therefore, targeting children who report poor cognitive reappraisal processes may alleviate maladjustment post peer-victimisation. 
Running Head: EMOTION REGULATION VICTIMISATION COPING

\section{References}

Aldao, A., Nolen-Hoeksema, S., \& Schweizer, S. (2010). Emotion-regulation strategies across psychopathology: A meta-analytic review. Clinical Psychology Review, 30(2), 217-237. doi: $\underline{10.1016 / j . c p r .2009 .11 .004}$

Andreou, E. (2001). Bully/victim problems and their association with coping behaviour in conflictual peer interactions among school-age children. Educational Psychology, 21(1), 59-66. doi: $\underline{10.1080 / 01443410125042}$

Asher, S. R., Hymel, S., \& Renshaw, P. D. (1984). Loneliness in children. Child Development, 55, 1456-1464. doi: $\underline{0.2307 / 1130015}$

Cole, P. M., Martin, S. E., \& Dennis, T. A. (2004). Emotion regulation as a scientific construct: Methodological challenges and directions for child development research. Child Development, 75(2), 317-333. doi: 10.1111/j.1467-8624.2004.00673.x

Eslea, M. (2001). School bullying: Severity, distress and coping. British Psychological Society Centenary Annual Conference, SECC, Glasgow, 28 - 31 March.

Flanagan, K. S., Hoek, K. K. V., Shelton, A., Kelly, S. L., Morrison, C. M., \& Young, A. M. (2013). Coping with bullying: What answers does children's literature provide?. School Psychology International, 34(6), 691-706. doi:10.1177/0143034313479691

Garnefski, N., Kraaij, V., \& Spinhoven, P. (2001). Negative life events, cognitive emotion regulation and emotional problems. Personality and Individual differences, 30(8), 1311-1327. doi:10.1016/S0191-8869(00)00113-6

Gross, J. J. (1998). Antecedent-and response-focused emotion regulation: divergent consequences for experience, expression, and physiology. Journal of personality and social psychology, 74(1), $224-237$.

Gross, J. J. (2013). Emotion regulation: Taking stock and moving forward. Emotion, 13(3), 359 - 365. doi: $10.1037 / \mathrm{a} 0032135$ 
Running Head: EMOTION REGULATION VICTIMISATION COPING

Gross, J. J., \& John, O. P. (2003). Individual differences in two emotion regulation processes: implications for affect, relationships, and well-being. Journal of Personality and Social Psychology, 85(2), 348. doi:10.1037/0022-3514.85.2.348

Gullone, E., Hughes, E. K., King, N. J., \& Tonge, B. (2010). The normative development of emotion regulation strategy use in children and adolescents: A 2-year follow-up study. Journal of Child Psychology and Psychiatry, 51(5), 567-574. doi: 10.1111/j.1469-7610.2009.02183.x

Gullone, E., \& Taffe, J. (2012). The Emotion Regulation Questionnaire for Children and Adolescents (ERQ-CA): A psychometric evaluation. Psychological Assessment, 24(2), 409 - 417.

doi:10.1111/j.1469-7610.2009.02183.x

Hansen, T. B., Steenberg, L. M., Palic, S., \& Elklit, A. (2012). A review of psychological factors related to bullying victimization in schools. Aggression and Violent Behavior, 17(4), 383-387. doi:10.1016/j.avb.2012.03.008

Harper, B. D. (2012). Parents' and children's beliefs about peer victimization attributions, coping responses, and child adjustment. The Journal of Early Adolescence, 32(3), 387-413. doi:10.1177/0272431610396089

Hessler, D. M., \& Fainsilber Katz, L. (2007). Children's emotion regulation: Self-report and physiological response to peer provocation. Developmental Psychology, 43(1), 27 - 38. doi: $\underline{10.1037 / 0012-1649.43 .1 .27}$

Houbre, B., Tarquinio, C., \& Lanfranchi, J. B. (2010). Expression of self-concept and adjustment against repeated aggressions: the case of a longitudinal study on school bullying. European Journal of Psychology of Education, 25(1), 105-123. doi:10.1007/s10212-009-0005-x

Hunter, S. C., \& Borg, M. G. (2006). The influence of emotional reaction on help seeking by victims of school bullying. Educational Psychology, 26(6), 813-826. doi: $\underline{10.1080 / 01443410600941946}$

Hunter, S. C., Boyle, J. M., \& Warden, D. (2004). Help seeking amongst child and adolescent victims of peer-aggression and bullying: The influence of school-stage, gender, victimisation, appraisal, and emotion. British Journal of Educational Psychology, 74(3), 375-390. 


\section{Running Head: EMOTION REGULATION VICTIMISATION COPING}

Katz, L. F., Maliken, A. C., \& Stettler, N. M. (2012). Parental meta-emotion philosophy: A review of research and theoretical framework. Child Development Perspectives, 6(4), 417-422. doi: 10.1111/j.1750-8606.2012.00244.x

Kochenderfer-Ladd, B., \& Pelletier, M. E. (2008). Teachers' views and beliefs about bullying: Influences on classroom management strategies and students' coping with peer victimization. Journal of School Psychology,46(4), 431-453. doi:10.1016/j.jsp.2007.07.005

Larsen, J. K., Vermulst, A. A., Eisinga, R., English, T., Gross, J. J., Hofman, E., ... \& Engels, R. C. (2012). Social coping by masking? Parental support and peer victimization as mediators of the relationship between depressive symptoms and expressive suppression in adolescents. Journal of youth and adolescence, 41(12), 1628-1642.

Mahady-Wilton, M. M., Craig, W. M., \& Pepler, D. J. (2000). Emotional regulation and display in classroom victims of bullying: Characteristic expressions of affect, coping styles and relevant contextual factors. Social Development, 9(2), 226-245. doi:10.1111/1467-9507.00121

McRae, K., Gross, J. J., Weber, J., Robertson, E. R., Sokol-Hessner, P., Ray, R. D., ... \& Ochsner, K. N. (2012). The development of emotion regulation: an fMRI study of cognitive reappraisal in children, adolescents and young adults. Social cognitive and affective neuroscience, 7(1), 1122. doi: $\underline{10.1093 / \mathrm{scan} / \mathrm{nsr} 093}$

Muthén, L. K., \& Muthén, B. O. (2012). Mplus statistical modeling software: Release 7.0. Los Angeles, CA: Muthén \& Muthén.

Mynard, H., \& Joseph, S. (2000). Development of the multidimensional peer-victimization scale. Aggressive Behavior, 26(2), 169-178. doi:10.1002/(SICI)10982337(2000)26:2\%3C169::AID-AB3\%3E3.3.CO;2-1

NSPCC. (2015). ChildLine Annual Review 2014-15. Retrieved from: https://www.nspcc.org.uk/globalassets/documents/annual-reports/childline-annual-reviewalways-there-2014-2015.pdf

Podsakoff, P. M., MacKenzie, S. B., Lee, J. Y., \& Podsakoff, N. P. (2003). Common method biases in behavioral research: a critical review of the literature and recommended remedies. Journal of Applied Psychology, 88(5), 879 - 903. doi:10.1037/0021-9010.88.5.879 


\section{Running Head: EMOTION REGULATION VICTIMISATION COPING}

Preacher, K. J., \& Hayes, A. F. (2008). Asymptotic and resampling strategies for assessing and comparing indirect effects in multiple mediator models. Behavior research methods, 40(3), 879-891. doi:10.3758/BRM.40.3.879

Rose, J., Gilbert, L., \& McGuire-Snieckus, R. (2015). Emotion coaching: a new approach to supporting children's behaviour in schools. European Journal of Behavioural Sciences, 13, 1766-1790.

Rose, A. J., \& Rudolph, K. D. (2006). A review of sex differences in peer relationship processes: potential trade-offs for the emotional and behavioral development of girls and boys. Psychological Bulletin, 132(1), 98 - 131. doi:10.1037/0033-2909.132.1.98

Schreiber, J. B., Nora, A., Stage, F. K., Barlow, E. A., \& King, J. (2006). Reporting structural equation modeling and confirmatory factor analysis results: A review. The Journal of Educational Research, 99(6), 323-338. doi:10.3200/JOER.99.6.323-338

Smith, P. K., Talamelli, L., Cowie, H., Naylor, P., \& Chauhan, P. (2004). Profiles of non-victims, escaped victims, continuing victims and new victims of school bullying. British Journal of Educational Psychology, 74(4), 565-581.

Snyder, C. R. (1999). Coping: The Psychology of what Works. New York: Oxford University Press

Steinberg, L. (2005). Cognitive and affective development in adolescence. Trends in Cognitive Sciences, 9(2), 69-74. doi:10.1016/j.tics.2004.12.005

Ttofi, M. M., Bowes, L., Farrington, D. P., \& Lösel, F. (2014). Protective factors interrupting the continuity from school bullying to later internalizing and externalizing problems: A systematic review of prospective longitudinal studies. Journal of School Violence, 13(1), 5-38. doi: $10.1080 / 15388220.2013 .857345$

Webb, T. L., Miles, E., \& Sheeran, P. (2012). Dealing with feeling: a meta-analysis of the effectiveness of strategies derived from the process model of emotion regulation. Psychological Bulletin, 138(4), 775 - 808. doi: $\underline{10.1037 / a 0027600}$

Zeman, J., Cassano, M., Perry-Parrish, C., \& Stegall, S. (2006). Emotion regulation in children and adolescents. Journal of Developmental \& Behavioral Pediatrics, 27(2), 155-168. doi:10.1097/00004703-200604000-00014 
Running Head: EMOTION REGULATION VICTIMISATION COPING

Zimmer-Gembeck, M. J., \& Skinner, E. A. (2011). Review: The development of coping across childhood and adolescence: An integrative review and critique of research. International Journal of Behavioral Development, 35(1), 1-17. 